\title{
An Investigation on the Consequences of Mal-traditional Practices: The Case of Indigenous People in State of Benishangul Gumuz
}

\author{
Shewa Basizew \\ M.Ed in English as a foreign language \\ Abebe Ano \\ Assistant Professor of History and Phd candidate \\ Atnafu Morka \\ Assistant Professor in Geography and Environmental Study
}

\begin{abstract}
In today's Ethiopia where challenges on development is made by indigenous people in regions, State of Benishangul Gumuz region is extending its effort towards reaching excellence in all aspects including health and societal matters. As part of the country's effort, Benishangul Gumuz region in general and Assosa University in particular carries out various studies based on scientific plans for scaling up its achievements constantly. However, Mal-traditional practices (MTP's)-Festival Ceremony, marriage related practices (early marriage, Abduction marriage, Bride wealth payment and inheritance marriage), domestic violence and skin cutting) are the most prevalence and challenge phenomena among indigenous people of the region. Thus, this study was aimed at assessing on the effects of mal-traditional practices among indigenous people in State of BenishangulGumuz Region. In doing so, the study particularly attempted to examine the level (prevalence) and impact of these mal-traditional practices on socio-economic and health conditions of indigenous people in study areas. To identify the factors hindering government officials in eliminating mal-traditional practices among the indigenous people in the region. The study was designed to be survey where quantitative and qualitative data were gathered through questionnaire. The questionnaire consists of both open-ended and close-ended items. Focus group discussions was made on the indigenous people to collect relevant information. Besides to these, an interview was made with experts and political appointees. Hence, 93 people were involved in the study in filling the questionnaire, 20 people interviewed and 90 people in FGD. Therefore, 203 people were totally the target groups of the study. Results of the study indicated that, the society had knowledge about the prevalence of harmful traditional practices. In the same manner, the society held a kind of favorable practice against MTP's although there remained many people in the society who still ignored and wanted to see their co-existence with the MTP's. As far as practice is concerned, it was found out that MTP's was exercised in their respective areas among indigenous communities, by a large number of people, for diverse reasons(social, economic, cultural cases). Eventually, based on the data interpreted and analyzed, conclusions are made, and recommendations are forwarded.
\end{abstract}

Keywords:Mal-traditional practices (MTP's), prevalence, Practices, marriages, festivities, State of Benishangul Gumuz region.

DOI: $10.7176 / \mathrm{JCSD} / 47-01$

Publication date: April $30^{\text {th }} 2019$

\section{Introduction}

Ethiopia today, with over 90 million people, the third largest country in Africa, has a great number of ethnic groups, whose cultures are as rich and varied as their composition. Consequently, Ethiopia has ample traditional practices to offer to the other parts of the country. The traditions have deep historical roots. The respect for traditions have been considered as one of the dominant characteristics of Ethiopians (Amare Dejene\& Aster Birhanselase, 2006:10). Despite of this fact, by mal-traditional practices, we mean all practices done deliberately by human being on the body or the consciousness of other human beings for no beneficial purpose, but rather for cultural or socio-conventional intentions and which have harmful consequences on the health and the rights of the victims. As such, these practices have negative impacts often permanently on the life of the girl, the boys, the women, the children, the mother, the husband or their family members; it is therefore, a societal phenomenon (Morissand Akouyaté, May 2009:1)

On the other hand, some traditional practices such as early marriage, Abduction, Exchange Marriage, Festivals, Bride-wealth payment, Inheritance marriage, Funerals, Domestic violence, skin cutting practices and others have the effect of jeopardizing the health of the population and interfere with human rights of the individual who conforms to the practice. These should be dealt with and eradicated from the country in general and state of Benishangul Gumuz region in particular. However, every culture has its ways of valuing women, children, girls and boys, and assigns different patterns of behaviors, attitudes, roles, rights, responsibilities and 
expectations in the socialization process (Awoke Bayehetail, 2015). So this is the case for prevalent of maltraditional practices among indigenous people in the State of Benishangul-Gumuz region. These indigenous people of the region have various types of mal-traditional practices which they experienced in their daily life. Thus, the mal-traditional practices such as Early marriage, Abduction, Exchange Marriage, Festivals, Bride wealth payment, Inheritance marriage, Funerals, Domestic violence, skin cutting practices and others are reflected within the family and community at large(Abebe Ano: 2010).

Researchers like Awoke Bayeh etail (2015) have studied on mal-traditional practices, giving attention on the level of the society's knowledge of traditional practices, the causes that contribute for the occurrence of maltraditional Practice, its prevalence and attitude of the community towards the practices in Amara region. Additionally, Kalkidan Bekele (2007) has conducted study on cultural practices that affected the status of women in Benishangul Gumuz Madura Woreda with specific emphasis on gender relation and gender based division of labor, right of women in the making and use of resources and participation of women in the decision making. But, these previous studies lacked in depth consideration of festivals, marriage related practices such as early marriage, inheritance marriage, exchange marriage, polygamy, and abduction) domestic violence and skin cutting practices which are widely practiced in the region. In conclusion, a comprehensive study of maltraditional practices among indigenous people in State of Benishangul-Gumuz Region has not yet been thoroughly studied. Hence, the major purpose of this research is to investigate the long period unexplored malttraditional practices of indigenous people of the region.

Hence, the very objectives of this study was to examine the level (prevalence) of mal-traditional practices (festivals, marriage related practices, domestic violence and skin cutting) among indigenous people of the region and to explore the effects of these mal-traditional practice son socio-economic and health conditions of indigenous people in study area.

This study was conducted within three (3) zones of Benishangul-Gumuz Regional state but it was undertaken only within 7 sampled Woredas. Although there are different MTPs (Mal-traditional Practices) practiced in the Benishangul Gumuz region, the study focused on commonly known and practiced ones that include, festivals, marriage related practices (early marriage, Abduction, Bride wealth Payment, Inheritance Marriage), domestic violence and skin cutting.

\section{Research Design and Methodology}

\subsection{The Study Area}

Benishangul-Gumuz Regional State (BGRS) is one of the nine Federal Regions of Ethiopia situated in north western part of the country. It shares boundaries in the northern and north eastern with Amhara region, in the east with Oromia region, in the south with Gambella region and in the west with Republic of Sudan (Benishangul-Gumuz Regional State Revised constitution, 2002).

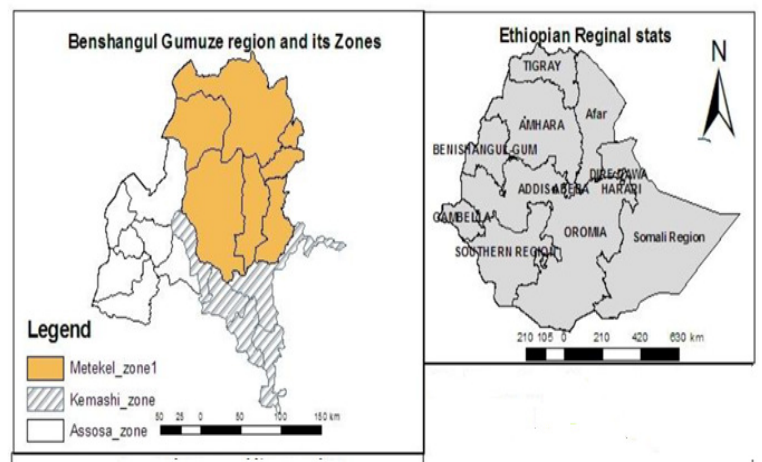

\subsection{The People in the Study Area}

There are five indigenous people living in state of Benishangul-Gumuz region. These are Gumuz, Shinasha, Berta, Mao and Komo. Linguistically, each has their own classes. Gumuz people belong to the Nilo-Saharan language family; according to TaddaseTamarat, they are among the earliest inhabitants of the Metekkel and originally occupied extensive territory that extended to the shores of Lake Tana and the Abbay basin. At present most of these people are living in the hot low-lands of Metekkel, Metemma and surrounding areas and Kamashi zone. Agriculture is the main occupation of the society and an individual can farm as much land as he can inside the territory of the clan. The Archaic agricultural tools and the size of labor that he receives during the working seasons limited his /her work not to plough and possess more than two hectares. The society cultivates many kinds of crops-sorghum, corn, millet; groundnut, cotton, tobacco and pumpkins are the most important. Fishing, hunting and gathering are also additional economic activities. But, the society does not own large livestock. The Gumuz people are also known for their honey production (Abebe: 2010:3) 
The Shinasha are also one of the indigenous people, who live in region and have different cultural, economic and social practices that distinct them from others. The main economic activity of the Shinasha people is agriculture. They produce crops-sorghum, millet, corn, pumpkins, cotton and others. They reared various animals -cattle, to satisfy their need of food items. A small number of the society engages on hunting and gathering fruits and roots (Abebe: 2010:8). According to oral traditions of the society, the Shinasha people were one of the early settlers of the region. They have had their own language, which is called Borenona'a. Borenona' $a$ literally it meant the Shinasha language and it is spoken in most parts of the region (ibid).

Berta, the indigenous people in the region belongs to the Nilotic language family. According to local traditions, the Berta occupy overwhelming territory that extended to Eastern Sennar in Sudan, south of Abbay River, Assosa zone and surrounding areas of the region. Agriculture, trade in gold, hunting and collection of wild fruits and seeds are the basis for economic activity of the people (History and Culture of the Benishangul Gumuz People: A paper presented on the $9^{\text {th }}$ Nations, Nationalities and People Day: August, 2007).

Komo is also an indigenous people in the region and according to traditions of the people; they occupy much extensive territory that extended from Mountain of Bagiewa or Gawi to Horro District of Komi as far as Border of Sudan in West and district of Tongo and some Districts of Gambella Regional State. The economic activity of the Komo people is Agriculture (Ibid).

Finally, Mao is also an indigenous people in the region and according to local tradition, they occupied large areas extended to Border of Sudan in west, Oromia region of Anfilo, Kundala, Begie, Nejo, Mensibu, Daddessa, Metahara and Southern Nation, Nationalities and people region of Bonga areas and the surroundings and within the region particularly Mao and Komo Special district (Woreda) and Bambasi district and Bello-jengafo district. The economic basis of Mao people is agriculture and hunting (Ibid).

\section{Methodology}

In order to achieve the general and specific objectives of the study, mixed research approach was employed. The fundamental principle of mixed method in conducting research was that multiple kinds of data collected was with different strategies and ways that reflecting complementary strengths and non-overlapping weaknesses (Johnson and Turner 2003).Hence data was collected in seven Woredas sample areas of the targeted populationgovernmental offices and residents of the Woredas who have different background and experience through selfadministered questionnaire, semi- structured interviews. Thus, information collected in these manners was supported by focus group discussions and secondary data. Therefore, this study appeared or resulted from both qualitative and quantitative approaches.

\subsection{Sampling Techniques}

purposive sampling was used in line with focusing with the title of the study and sample areas where the so called indigenous people were living in the region.

\subsection{Sampling Woredas}

In Benishangul-Gumuz Region there are three zones and one special Woreda, namely Metekel Zone, Kamashi, Assosa and Tongo Special Woreda consisting seven, five, seven and 1 Woredas respectively. In Metekel Zone; Dangur, Debati and Bullen Woredas were purposely selected for the reason that Shinasha and Gumuz people reside there for centuries. In Kamashi Zone, Kamashi and Yaso Woredas were sample areas; because Gumuz people confined in these areas of the zone. In Assosa zone, Homosha and Bambassi were selected for the reason that Berta people are reside in these sites. In addition, Tongo special Woreda was selected where Mao and Komo people are to live.

\subsection{Methods: Data Collection Instruments}

The main instruments that the researchers used for data collecting purpose were questionnaire, interview and focus group discussion (FGD). Besides, Primary data was supported by analyzing secondary documents that were obtained from different offices in the region.

\section{Result Discussion and Data analysis}

In this section, data collected on malt-traditional practices were presented, analyzed and also integrately shown in the eyes of scholars' perspectives. The section dealt with more of qualitative data which comprised information obtained through questionnaire in open-ended questions, interview, and FGD about the types of maltraditional practices, the effects of harmful traditional practices and dealt with government policy implications. Each of the harmful traditional practices, i.e. Festivals, Marriage related practices (Early Marriage, Abduction marriage, Inheritance marriage, Bride wealth payment), Domestic violence, and Skin cutting practices, were discussed from the angles of society's knowledge gap and practice as well as level of prevalence. Nevertheless, the data which was obtained through questionnaire was analyzed quantitatively by using a simple mathematical 
expressions and integrated with data analyzed qualitatively.

The data collected and scientifically analyzed about the frequency of traditional practices, which were related with festivals and the extended practiced among the indigenous society reads that $41.9 \%$ and $25.8 \%$ of respondents respectively responded that as there was high and very high practice of mal-traditions which were festival related.

In the same way, the data obtained through open-ended questionnaires reveals that major problems of maltraditional practice in line with problems related with festivals "Taskar" and the wage paid during wedding ceremony. These common traditional practice were accompanied with extravagant or excessive loss of the money which was collected in the long time and owned by individuals. According to the indigenous informants, these traditional practices were highly exposed to culturing extravagantly use of money which finally was followed by happening of poverty in the society in the community. Depending on the information obtained from the local elders in Homosha Woreda the indigenous people did not have a practice on extravagancy use of economy in line with celebration of festivals and related ritual ceremonies. But, the researchers have looked in to the points neutrally and have observed that there exists extravagance use of economy on the case of celebration of cultural festivity.

Conversely, the data collected through Focus Group Discussions (FGD) from the community leaders shows that Gumuz society in Metekkel and Kamashi Zone, and Shinasha Society in Metekkel zone had a practice on lots of mal-traditions and had lots of bad experiences on it. Most of the mal-traditions practices were lifelong activities which were believed and taken as good habits or customs in the society; transformed from generation to generation though few were getting stopped and removed. For instant, "Taskar ceremony" is one of the most popular festivals highly celebrated in Gumuz and Shinasha society until today. In both Shinasha and Gumuz society there is still strong culture of supporting each other when celebrating the so called Taskar as ritual ceremony.

Furthermore, as stated by FGDs, the most rational behind celebrating for Taskar in Gumuz and Shinasha society is to look for glory, the respect that is given by the community-if one did not celebrate "Taskar" festivity he would not be respected rather undermined by the community members in every aspect of the life. Besides to the above community effect, celebrating Taskar is taken as means to keep the promise of the dead-the sprite of the dead would case something bad on the parents. Even, according to the information obtained from the indigenous people in Gumuz society, before the body is buried a big oxen is provided to those who avail on the funeral ceremony and then after the body is buried much money which is almost 4,000-7,000.00 birr is collected from the funeral participants and would be given back to the parents to cover the expense. On the bases of the information obtained from the literate indigenous people about five goat, five sheep, uncounted number of cock, local drunks (Araki and Bordi,), more than three oxen based on the largeness of tribes coming to festivity would be provided for the celebration Taskar; So that 50-70,000 ETB expectedly consumed on the occasion. But, after hotly celebrating the Taskar festivity many of them would have failed to support, their parents and themselves economically. They become dependent and became exposed to problems-unable to manage the family. In this case, the interview made with leaders and political delegates read that all sources of extravagant loses of expense are mal-traditional practices and in turn should be removed

In contrast, the result of interview-open ended questions and the Focus Group Discussion (FGD) show that in the culture of Mao and Komo people, there was no festival practices that brought challenges on the growth of economy of the community. But, it did not mean that there was no celebration of festivity but, it mean that there was no high extravagancy practice that would affect the economy.

The study also examined the extent of mal-traditional practices more particularly early marriage related practice among the indigenous people. Accordingly, 35.5. \% and 23.7\% of the respondents rated that the extent of early marriage was low and very low respectively in the region, where as $11.8 \%$ and $29.9 \%$ of the respondents rated as very high and high respectively. Consequently, one could possibly judge that there is low practice of early marriage within the society based on the data obtained from the sample study areas; despite this fact some very insignificant practices are realized. This indicated that, the study reveals that there has been some degrees of the practice. From its implication one could possibly conclude that early marriage and its actual practice is becoming decreasing in the region.

Some years ago, little young females were suffering from fistula which is resulted from the happening of early marriage where the girl is not physically matured and sexually ready. But, according to major informants and the interview conducted in sample areas show that early marriage practices is not common by now and as a result prevailed rarely in general all areas of the region and particularly in the Berta community. Hence, the study shows that the condition of early marriage has come declined.

However, some of the Gumuz people experienced in participating on early marriage; especially in the peripheral areas of Kamashi zone. According to some political delegates in Kamashi zone, Yaso woreda a little young girl is forced to marry an old man who is with 50-55years old and who had experienced marriage ahead, though its degree becomes decreasing due to the active involvement of politicians (higher and medium officials 
and police).

The study reveals that the abduction marriage practice among the indigenous society is becoming low in the region. That is $45.2 \%$ and $25.8 \%$ of the respondents reaction portrays that its practice among the indigenous society is rated as low and very low respectively. But, it does not mean that as it was not purely taking place, rather $17.2 \%$ and $11.8 \%$ of the respondent's data shows high and very high respectively and there exists some practice of abduction marriage in the region across the three zones and the special zone. Abduction marriage was one of the traditional practices on the indigenous people in the region even though the data obtained in this study displayed a low practice among the society. According to some elder informants communicated in the sample selected study areas, some years ago youth's abduction marriage was regularly practiced-those who failed to pay the requested wage to the girl's parent. Lots of money is invested to the girl's family. The wage could be in kind or in cash. As result, the young man was forced to have abduction marriage to have his beloved couple. But, now days, this practice has come reduced in cited areas-Kamashi and Yaso and Mao-Komo special woredas. Moreover, the data obtained through interview, open ended questionnaires and focus group discussions made with local elders shows that the situation is declining for the reason it banned by law.

Finally, it could be concluded that mal-traditional practice related with abduction marriage occurred in the study areas has become decreased in the regions.

In this study, the researchers' needs to check the extent of mal-traditional practices related with inheritance marriage among society. Accordingly, 37.6\% and 33.3\% respondents' data revealed that inheritance marriage is very low and low respectively practiced among the indigenous society in the region. To this contrary, $14 \%$ and $15.1 \%$ of the respondents in the sample areas agreed that as there was high and very high inheritance marriage practice in the region. Therefore, this indicates that as there was some degree of the practice. So that, as it is shown on the above table the extent of the inheritance marriage practice is very low and decreasingly coming yet there was a culture in which the community practices it.

According to the information obtained from the indigenous informants, inheritance marriage is one of the type of marriage which was carried out by the community members in the region though its outrange has come reduced due to the blooming of civilization and fear of HIV and other sexually transmitted diseases(STDs). In the region, inheritance marriage was taking place as the case of supporting the dead man's family-to look after the property of the dead man and the children to protect the family from someone else in other tribal family. Therefore, the woman should be inherited by the one who has kin relationship with her former husband whether she likes or not. As a result, keeping the property and family of the dead man was taken as culture and predispositional condition to inherit the woman. So that, the man is vested responsibility to discharge everything as head of the family.

As stated further by local elders in study areas, inheritance marriage was one of the marriage which was taking place in Gumuz society in Kamashi, Metekkel and Assosa zone and Mao-Komo in Tongo special Woreda. This was happened when a man from a certain tribe was died or passed away and one of his closed families from the same tribe was forced to marry the woman whose husband was died. The rationale behind was to support the dead man's family socially and economically. This was one of the popular traditions in the indigenous society in the region. But, this bad tradition is almost going to be stopped by now. This inheritance marriage was happening without making blood test. It opens doors to the newly married couples for different diseases-HIV and Gonoria. That is why it is forced to be stopped. Despite this fact, it is rarely practiced in the territorial areas of Gumuz society in Kamashi zone and Tongo Woreda.Moreover, exchange marriage was one of the great headache which was not easily removed from the indigenous society, particularly in the Gumuz society in Kamashi zone-Kamashi and Yaso Woredas. It was practiced for longer and longer time though at the verge of stopping by now. The severe problem of this types of marriage is that the young man is forced to divorce his beloved young wife for the reason that his sister has made divorce ahead and come back to her parents-if she did not love her husband, she would leave for her parent's home and her brother is forced to divorce his wife on behalf.

The data collected and carefully analyzed depicts that bride wealth payment was one of the series agenda among the indigenous people of Benishangul-Gumuz Regional State. Accordingly, $28.0 \%$ and $33.3 \%$ respondents replied that as there was very high and high practice of bride wealth payment among the indigenous society in the region respectively. Whereas $18.3 \%$ and $20.4 \%$ of the respondents also rated very low and low respectively that the prevalence of bride wealth payment. Besides to the data gathered through the close-ended questions, the information obtained through the focus group discussion made with community leaders and interview conducted with political delegates reveal that the indigenous people of the region more particularly Gumuz, Shinasha and Berta people are exposed to the culture of bride wealth payment. For instance, in the case of Kamashi, the young Gumuz boy is supposed to pay around 20-30,000 ETB and 10-15,000ETB in the case of Shinasha people in Metekkel. Besides, Oxen, sheep and goat are provided in-kind to the girl's parent, unless he could not marry the girl whom he loves in the community. In losing this tradition of marriage ceremony, the young boy would not have the opportunity to marry his beloved girl. 
Hence, based on FGD made with community leaders and interview made with literate persons in sample areas, bride wealth payment is the most sever mal-traditional practice which highly cases difficulty to the poor societal areas like Kamashi, Assosa and Metekkel zones. Based on the data gathered from the sample areas through all the data collecting tools, one could possibly concluded that the indigenous people of the region are highly or very highly exposed to the bride wealth payment which is the big part of the mal-traditional practice.

According to the information collected through Focus Group Discussion and interview, the domestic violence is also one of the dangerous experiences that happened regularly in the Gumuz society. The first domestic violence begins on the belief that woman is the pillar worker in covering the indoor and outdoor activities; the most important work is highly covered by her. If she fails to run these outdoor and indoor activities the communities condemned her as lazy woman of the community. The second one is that the little young girl is forced to collect fire wood for selling and in turn covering the house expense. Walking long distances from home to market areas the collected fire wood is sold to cover for the daily consumption expense. Besides, based on the information gained from the local elders in Kamashi woreda the woman is not culturally allowed to eat the foods like meat values which came from her father and mother in-laws. Unexpectedly, if she eats the mentioned food items, there is belief that says she is going to die. The same is true for the husband. To the contrary, there are important changes observed than the previous life experience on the indigenous Gumuz people; according to the local informants, initially, the woman was not allowed to bear her child at home; but this has come a history and she bears at health centers located nearby her home. Secondly, the first menstrual period was dangerous time to the girls in the Gumuz, and Mao and Komo society; she was treated alone in the nearby forest adjusting important services for only herself, until gets purified from the appearing menstrual period.

Regarding with skin cutting practice, respondents were asked to indicate their practice and its frequencies. Accordingly, $39.8 \%$ and $25.8 \%$ of the respondents rated that the practice is becoming very low and low respectively. The study reveals that the practice is getting reduced among Berta, Gumuz Mao and Komo communities in study areas. From this, it could be concluded that the practice of skin cutting which was taken as a culture on Berta, Gumuz and Mao-Komo becoming decreased. On the basis the data collected and analyzed, skin cutting is not totally ignored but, still exists in some areas where indigenous people are living in the region. Even, $17 \%$ of the respondents belief and answered as the skin cutting exists in some areas as expression of identity.

The key informants and FGD participants have explained that skin cutting is one of the mal-traditional practice in the region, especially which is commonly realized in the Berta, Gumuz Mao and Komo people, who live on territorial areas. This skin cutting deforms the natural beauty of those people which they endowed naturally, despite the fact they use it for increasingly show the shine of the beauty. However, it left legacy on their physical appearance or skin.

Furthermore, they claimed that the skin cutting practices has a conducive environment for the possible transmission of HIV/AIDS in the community. The public lacked education on the multiple modes of transmission of HIV/AIDS including MTPs.

\section{The Rationale Behind to Practice or Perpetuate MTPs}

Based on the data taken from the indigenous informants, there were some reasons which were thought as rationales in practicing for these mal-tradition activities in the region by the indigenous groups.

5.1. Socio-cultural reasons: - These mal-traditional practices are used to happen and perceived as valued cultures that were inherited from the early ancestors. For example, in Boro-Shinasha and Gumuz community, "Taskar" is regularly practiced for the reason that the sprite of the dead man would disturb the family. Instead, high amount of money is budgeted to process the situation which is externally aimed to free the soul of dead man from his sin. But, the implication of processing Taskar is to have recognition (Glory of the family) from the community. Because, persons who perform Taskar have great respect than those who cannot run it. In the same way, reasons for practicing inheritance marriage is to keep the property and family of the dead man safely and also to keep the woman not marry a man from other tribes.

As stated by local elders in sample areas the rationale behind in practicing abduction marriage is followed by lack of money from bride boy as bride wealth payment. Because, girls were considered as means of income generation when some ones appeals for marriage. Hence, the bride boy did not have any option unless forcing the girl to be his couple through abduction marriage.

Finally, participation of the woman in the outdoor and indoor activities or domestic activities was resulted due to the influence of the culture which has come down from the early forefathers and mothers.

Moreover, as explained by interviewee, obtained from open ended questions and results from focus group discussions, the various socio-cultural reasons given for the traditional practice were the case roots for its enhancement. For instance, local elders confirmed and justified that early marriage, abduction and bearing son from other woman is the culture inherited from the early ansters and is developed as a positive value of the 
tradition. More particularly, having the son beard from other woman is considered as socio-culturally establishing a family's pillar, who ensures continuity and protection of the family property.

Even though the problems have come minimized by now, it was happening for long time in the community in outrange. Here, it could be concluded that there was no influence of other ethnics cultural impact, but this mal-traditional practices were resulted from their own cultural valued earned. The most reasons for the traditional practices were beliefs of the community which transformed from one generation to the next.

According to some of the indigenous informants the socio-cultural reasons of mal-traditional practice in Gumuz society in the case of Kamashi Zone, in some selected woredas were fear of isolation, fear of loss of respect (dignity) and fear of undermining from the community which they live together. For instance, if the young man could not have great contribution in festivals like Taskar, and could not marry a girl in bride wealth payment way, he would be isolated, not respected, ignored and undermined in the tribes in which he was born and grew up.

5.2. Economic reasons: - There are some mal-traditional practice which are considered as sources of income generation. For instance, bride wealth payment, and domestic violence.

\section{The Level of Challenges that Hinder Government officials in Illuminating Harmful Traditional Practices.}

Some questions were raised to the respondent that aims to examine the level of challenges that hinder government policies in eliminating mal-traditional practices among indigenous communities of the region.

\subsection{Social Challenges}

\begin{tabular}{|l|l|l|l|}
\hline $\begin{array}{l}\text { The level of challenges that hinder governmental policies and ways of } \\
\text { illuminating harmful traditional practices(How often) }\end{array}$ & Frequency & Percent & Median \\
\hline Very Low & 15 & $16.1 \%$ & 3.0000 \\
\hline Low & 20 & $21.5 \%$ \\
\hline High & 34 & $36.6 \%$ \\
\hline very High & 24 & $25.8 \%$ \\
\hline Total & 93 & $100.0 \%$ & \\
\hline
\end{tabular}

Table. 1. Social challenges that hinders implementation of government polices

The data presented in above table shows that the level of challenges that hinder governmental policies and hinders ways of eliminating harmful traditional practices in Benishangul Gumuz regional state. Based on the data presented on the above table $36.6 \%$ of the respondents believed and rated as high for the reason that the government policies have social challenges to eliminate harmful traditional practices among indigenous people in the region. Additionally, an information obtained through interview and Focus Group Discussion reveal that, the politically delegated higher officials did not create awareness on mal-traditional practices, rather they were the most forehead practicinaires than anybody else.

According to some informants one of the biggest problems of mal-traditional practice is social out casting. The out casted member of the community did not have an opportunity to underway social values with other members of the community. Likewise, local elders explained that, a girl is forced to drop out her education and advised to marry. From these scholastic ideas, one could infer or conclude that the community has strong belief on its culture which were wrongly practiced due to lack of awareness.

As informant's explained that, so as to secure and obtain fertility and virginity of the little young daughter, untimely early marriage and abduction was taken as the solution by the young boy and others in the region. Culturally, a girl who is not coming with a virgin at her first marriage is considered as unfit to her husband's family life and is a disgrace to them. The groom would severely beat the bride, take away the entire dowry given to her and leave her out. The marriage is immediately dissolved. Therefore, girls are forced to get married early; so that, the above mentioned consequences will not happen. Moreover, early marriage has also practiced to increase fertility: If a girl marries earlier she would be expected to produce many children who would be well equipped mentally and physically. 


\subsection{Challenges due to Religion}

\begin{tabular}{|l|l|l|l|}
\hline $\begin{array}{l}\text { The level of challenges that hinder governmental policies and ways of } \\
\text { eliminating harmful traditional practices due to religion of one's own }\end{array}$ & Frequency & Percent & Mdian \\
\hline Very Low & 14 & $15.1 \%$ & 2.0000 \\
\hline Low & 36 & $38.7 \%$ \\
\hline High & 23 & $24.7 \%$ \\
\hline very High & 20 & $21.5 \%$ \\
\hline Total & 93 & $100.0 \%$ & \\
\hline
\end{tabular}

\section{Table .2. Challenges Resulted from Religious of one's own}

The data presented on above table also shows the challenges due to religion of one's own in Benishangul Gumuz regional state. Accordingly, the data presented, reveals that $38.7 \%$ of the respondents' response ensures that the challenge of religion was low.

\subsection{Challenges due to Economy}

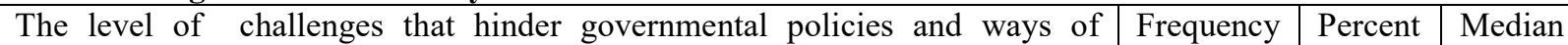
eliminating harmful traditional practices related to economy

\begin{tabular}{|c|c|c|c|}
\hline Very Low & 8 & $8.6 \%$ & \multirow[t]{5}{*}{3.0000} \\
\hline Low & 20 & $21.5 \%$ & \\
\hline High & 36 & $38.7 \%$ & \\
\hline very High & 29 & $31.2 \%$ & \\
\hline Total & 93 & $100.0 \%$ & \\
\hline
\end{tabular}

\section{Table .3. Challenges Related with Economy}

The data presented in above table depicts that the level of challenges that hinder governmental policies and ways of eliminating harmful traditional practices in relation to economic aspects in Benishangul Gumuz regional state. So that, the data presented depicts all the facts out ranged from very low to very high and $38.7 \%$ of the respondents responded that the level of challenges in line with economy as a hindering factors is very high which affects government policies not to be implemented in reducing the challenges. On the other hand, insignificant figures of data reads that very low showing that there was not any factor related with economy that hinders the implementation of the policy on the subject. Therefore, it becomes easy to infer that the level of the challenges in economy as a hindering factor was very high.

Likewise, the interview conducted with local elders shared the above notion and explained that in most of rural areas of the region, economic status of the society urged the family to run the condition. Due to this economical constrains early marriage and abduction marriage were overwhelmingly taking place in the region.

7. The opportunities of Training the Community

\begin{tabular}{|l|l|l|l|}
\hline Access to short term trainings \& opportunities for communities & Frequency & Percent & Median \\
\hline Very low & 24 & $25.8 \%$ & 2.0000 \\
\hline Low & 38 & $40.9 \%$ \\
\hline High & 18 & $19.4 \%$ \\
\hline very High & 13 & $14.0 \%$ \\
\hline Total & 93 & $100.0 \%$ & \\
\hline
\end{tabular}

Table 4. Short Term Trainings

Training is a means or a tool to address governmental policies to the community members in the prevention of mal-traditional practice and its harmful effects, on the economy, social and health aspects. From the data displayed on above table, one could infer that the culture and experience of offering short-term training to the communities in order to create awareness in line with government police on mal-traditional practice was low. Hence, $40.9 \%$ and $25.8 \%$ of respondents replied that the culture and experience of offering short-term trainings for the society reads low and very low respectively. Therefore, it would be deduced that that the experts or concerned bodies were not warmly engaged on awareness creation program through short term-training programs.

As different informants discussed on the subject, the short term trainings regarding mal-traditional practices were rarely given by NGOs for selected few Kebele leaders/administrators. But, there has not been trainings accessed for the wider community in general case. The training regularly invites the same persons day after day 
or month after month and even year after year. Therefore, this creates problems on fairness and cascading the training and its wide concepts in the prevention of harmful practices which were resulted from mal-traditional practices. Shortly, the study reveals that short-term trainings were not effectively and extensively offered to the society.

\begin{tabular}{|l|l|l|l|}
\hline Access to long term trainings its opportunities & Frequency & Percent & Median \\
\hline Very Low & 46 & $49.5 \%$ & 2.0000 \\
\hline Low & 29 & $31.2 \%$ & \\
\hline High & 5 & $5.4 \%$ & \\
\hline very High & 13 & $14.0 \%$ & \\
\hline Total & 93 & $100.0 \%$ & \\
\hline
\end{tabular}

\section{Table 5. Long Term Training}

Table 5 displays that there was no culture and experience of offering long-term trainings on mal-traditional practices and on its harmful effects to the society. Meanwhile, $49.5 \%$ and $31.2 \%$ of the respondents agreed that the culture and experience of offering long-term training to the indigenous people on mal-traditional practice was very low and low. Based on the this scientific study, procedurally gathered information from the target groups show that there was not long term trainings offered to the indigenous community members in general and community leaders in particular on the effects of harmful traditional practices.

8.The Impact of Malt-traditional Practices

Show the impact of mal-traditional practices in ticking as Very high (4) high (3) low (2) very low (1) from the illustrated Scales.

\begin{tabular}{|c|c|c|c|c|c|c|c|c|c|c|c|c|c|c|c|c|}
\hline \multirow[b]{2}{*}{ No } & \multirow{2}{*}{$\begin{array}{l}\text { Type of } \\
\text { Mal- } \\
\text { traditional } \\
\text { Practices }\end{array}$} & \multicolumn{5}{|c|}{ Social impact } & \multicolumn{5}{|c|}{ Economic impact } & \multicolumn{5}{|c|}{ Health impact } \\
\hline & & 4 & 3 & 2 & 1 & Total & 4 & 3 & 2 & 1 & Total & 4 & 3 & 2 & 1 & Total \\
\hline \multirow[t]{2}{*}{2.1} & Festivals & 46 & 28 & 10 & 9 & 93 & 62 & 27 & 1 & 3 & 93 & 44 & 25 & 15 & 9 & 93 \\
\hline & Percent (\%) & 49.5 & 30.1 & 10.8 & 9.7 & 100.0 & 66.7 & 29.0 & 1.1 & 3.2 & 100.0 & 47.3 & 26.9 & 16.1 & 9.7 & 100.0 \\
\hline \multirow[t]{2}{*}{2.2} & $\begin{array}{l}\text { Early } \\
\text { Marriage }\end{array}$ & 48 & 21 & 11 & 13 & 93 & 42 & 37 & 11 & 3 & 93 & 66 & 14 & 6 & 7 & 93 \\
\hline & $\begin{array}{l}\text { Percent } \\
(\%)\end{array}$ & 51.6 & 22.6 & 11.8 & 14.0 & 100.0 & 45.2 & 39.8 & 11.8 & 3.2 & 100.0 & 71.0 & 15.1 & 6.5 & 7.5 & 100.0 \\
\hline \multirow[t]{2}{*}{2.3} & $\begin{array}{l}\text { Abduction } \\
\text { marriage }\end{array}$ & 51 & 19 & 8 & 15 & 93 & 40 & 28 & 14 & 11 & 93 & 52 & 19 & 9 & 13 & 93 \\
\hline & $\begin{array}{l}\text { Percent } \\
(\%)\end{array}$ & 54.8 & 20.4 & 8.6 & 16.1 & 100.0 & 43.0 & 30.1 & 15.1 & 11.8 & 100.0 & 55.9 & 20.4 & 9.7 & 14.0 & 100.0 \\
\hline \multirow[t]{2}{*}{2.4} & $\begin{array}{l}\text { Inheritance } \\
\text { Marriage }\end{array}$ & 38 & 20 & 16 & 19 & 93 & 38 & 27 & 19 & 9 & 93 & 56 & 16 & 8 & 13 & 93 \\
\hline & $\begin{array}{l}\text { Percent } \\
(\%)\end{array}$ & 40.9 & 21.5 & 17.2 & 20.4 & 100.0 & 40.9 & 29.0 & 20.0 & 9.7 & 100.0 & 60.2 & 17.2 & 8.6 & 14.0 & 100.0 \\
\hline \multirow[t]{2}{*}{2.5} & $\begin{array}{l}\text { Bride } \\
\text { wealth } \\
\text { payment }\end{array}$ & 50 & 15 & 13 & 15 & 93 & 56 & 23 & 8 & 6 & 93 & 45 & 17 & 20 & 11 & 93 \\
\hline & $\begin{array}{l}\text { Percent } \\
(\%)\end{array}$ & 53.8 & 16.1 & 14.0 & 16.1 & 100.0 & 60.2 & 24.7 & 8.6 & 6.5 & 100.0 & 48.4 & 18.3 & 21.5 & 11.8 & 100 \\
\hline \multirow[t]{2}{*}{2.6} & $\begin{array}{l}\text { Domestic } \\
\text { violence }\end{array}$ & 42 & 30 & 17 & 4 & 93 & 36 & 33 & 20 & 4 & 93 & 51 & 25 & 12 & 5 & 93 \\
\hline & $\begin{array}{l}\text { Percent } \\
(\%)\end{array}$ & 45.2 & 32.3 & 18.3 & 4.3 & 100 & 38.7 & 35.5 & 21.5 & 4.3 & 100.0 & 54.8 & 26.9 & 12.9 & 5.4 & 100.0 \\
\hline \multirow[t]{2}{*}{2.7} & $\begin{array}{l}\text { Skin } \\
\text { cutting }\end{array}$ & 39 & 16 & 17 & 21 & 93 & 40 & 19 & 19 & 15 & 93 & 60 & 13 & 5 & 15 & 93 \\
\hline & $\begin{array}{l}\text { Percent } \\
(\%)\end{array}$ & 41.9 & 17.2 & 18.3 & 22.6 & 100.0 & 43.0 & 20.4 & 20.4 & 16.1 & 100.0 & 64.5 & 14.0 & 5.4 & 16.1 & 100.0 \\
\hline
\end{tabular}

\section{Table 6.The Impact of Mal-traditional Practices}

So as to check for the impact of mal-traditional practices, on the indigenous group of the society in relation with economic, social and health, the researchers have put the data clearly as depicted on table 4.5. Accordingly, the table shows the bad effect of festivals on social, economic and health aspects. It means that, most of the people perceived festivals always followed by negative out puts which directly affect the life of the community in short and long run plans. Following this, $49.5 \%, 67.7 \%$ and $47.3 \%$ of the respondents agreed that festivals did have very high negative impacts on social, economic and health aspects respectively. On the other hand, the information obtained through the FGD and interview approved that, soon after processing hot festivity during "Taskar" and bride wealth payment marriage the bride or the man is unable to lead himself as the former, regularly. Then, he is forced to steal and become theft. Finally, this young man has become dependent on his family, on the community and on the country broadly directly or in directly.

In the same disposition, most of the respondents explained their agreement that early marriage has impact on social, economic and health conditions, it was realized that most of the people perceived it to have a negative effect on the community. Hence, 48(51.5\%), 42(45.2\%) and 66(71.0\%) of respondents' verified that early marriage has very high effects on social, economic and health aspects of the indigenous community respectively. 
Besides to these, as deeply discussed by FGD participants the boy and the girl were faced with challenges of delaying and made drop out from schooling for the reason that their families warned and ordered them to have untimely marriage. So that, the early marriage conducted on the youths has a great problem on their upcoming lifespan both physically and emotionally. Even though early marriage underway knowingly or unknowingly in the community, it would have created imbalance on the social, economic and health aspects of the indigenous people.

Besides, abduction marriage, the other serious problem, which was harmfully affecting and made distortion on the social, economy and health parts of the community-the indigenous group. Consequently,51(54.8\%), $40(43.0 \%)$ and $52(55.9 \%)$ of the respondents rated very high respectively that abduction marriage has enumerate effects on the social, economic and health hood of the indigenous society.

According to these informants MTPs have adverse impact on the social well beings. Similarly maltraditional practices like domestic violence, early marriage and abduction marriage did have effects and limitations addressing education access to girls.

On the other manner, the study was touching about inheritance marriage and the way it was practicing among the community of the indigenous people. As a result, 38(40.9), 38(40.9\%) and 56(60.2\%) of the respondents agreed and rated that the impacts were very high respectively which shows abduction marriage has the negative impact on the life condition of the society, more particularly to the indigenous groups socially, economically and affect also the health condition.

Based on the data obtained from the interview and FGD, the most difficulty or problem of abduction marriage is the prevalence of physical and psychological hurt permantely or temporarily. The bride girl might be faced with HIV and other sexually transmitted related diseases-there was no opportunity to have medical examination ahead the marriage. As a result, the bride woman would be faced with long run effect on her physical and also her emotion.

In connection with inheritance marriage, Ethiopian Federal Inheritance Protection authority (2012), puts this as without any psychological readiness, women's are forced to remarry if their husband went away. This followed by many repercussions such as sexual abuse unwanted pregnancy, and responsibility of looking for additional children.

Finally, the researchers were also aimed to deal about bride wealth payment in this scientific study. Meanwhile, almost all the respondents have the same kinds of thought on the idea that bride wealth payment is means to decline in life for the reason money collected for the last many years was easily consumed extravagantly within short time. Thus, 50(53.8\%), 56(60.2\%) and 45(48.4\%) of the respondents said that bride wealth payment has very high effects on the social, economic and health situation of the people in the region. Nevertheless, uncommon to other Woredas of the region, the practice of bride wealth payment-destructing economy of the community was not as such severe problem in the Mao and Komo Woreda. The payments were usually few hundreds of birr and goats or sheep. Hence, one can look at the following graph of bride wealth payment on socio-economic condition of local people in the region. 

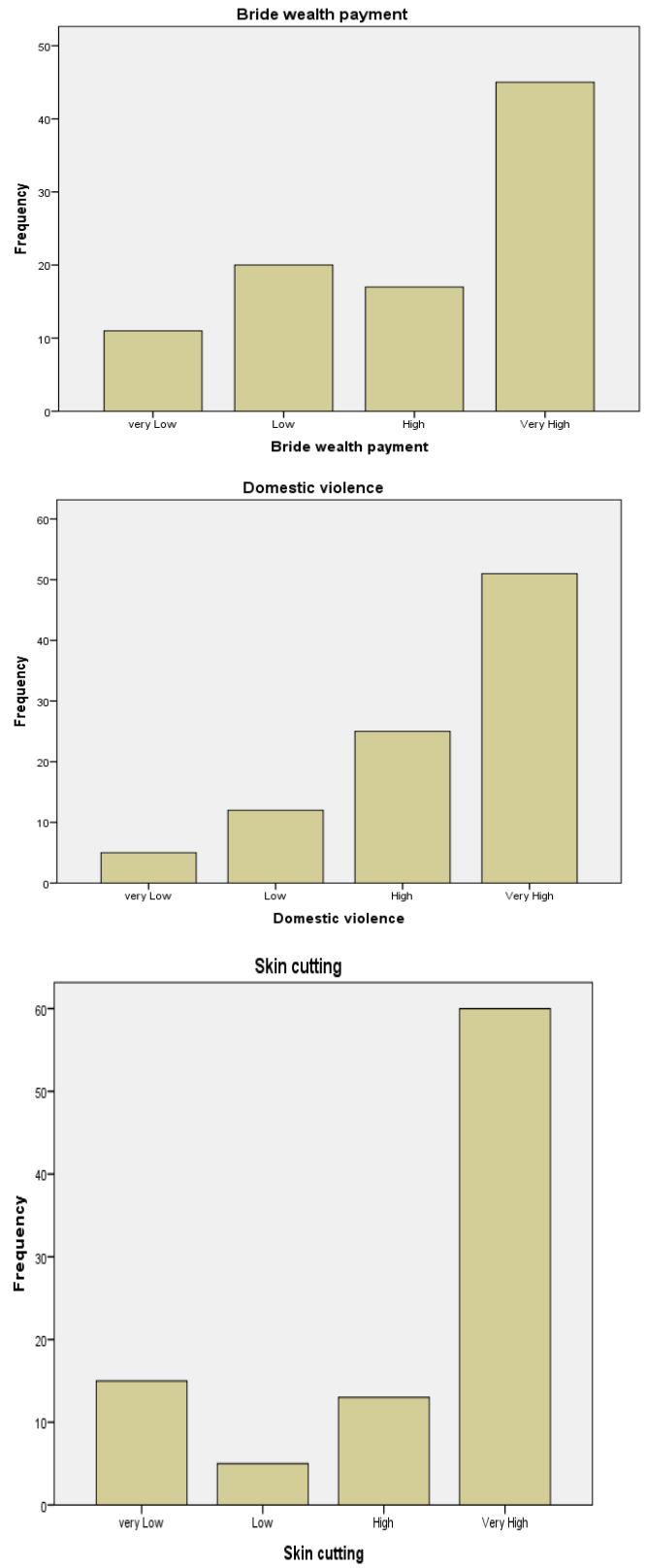

Skin cutting was one of traditional practice among indigenous communities of Gumuz, Berta, Mao and Komo. It was previously used for decoration- cut their lips and noses, root up one or two lower teeth; and also for identification purpose. 39(41.9\%), 40(43.0\%) and 60(64.5\%) of the representing sample respondents witnessed that skin cutting has negative impacts and consequences on the physical and emotional aspects life.

Generally, based on the ideas obtained through all the designed tools of the study from the target groups, the mal-traditional practices were highly severe and hampered the society socially, economically and to health problems. And even some of these mal-traditions were causes for sexually transitive disease-HIV\& Gonorrhea. Domestic violence is also other harmful practice, in which the greatest number of respondents $42(45.2 \%)$, $36(38.7)$ and 51(54.8\%) responded that women and children have challenges and faced very high consequence socially, economically and health conditions in the region. As informants claimed that, among the domestic violence, the most harmful practice that endangers life of females is an isolation made from social affairs such as ceremony and worship areas and stay in house alone. Another abusing against female right is quarrel with her husband which was resulted from drinking local alcohol and else type. After they had it, males usually try to harass even sexually.

\section{. Conclusion}

Based on the data analysis made in the previous chapters, the following points are derived as the major findings lead to conclusions. The level of prevalence of mal-traditional practices such as festivals, marriage related 
practices, early marriage, abduction marriage, inheritance marriage, bride wealth payment and domestic violence against women and girls and skin cutting were the harmful practices internalized among indigenous people of the region for long time.

- The extent of festival was highly practiced among the indigenous society in the region.

- The extent of early marriage at its outset was low practice and has come decreased, it was practiced rarely at the peripheral areas of the region

- Abduction marriage was in very low practice despite the fact that some data shows as there was some attempts (Practices) in Kebele's which are remote from the centers of each zones.

- Inheritance marriage was with low and very low practice in the region .It was reduced by the awareness creation program in connection was sexually Transmitted Disease(HIV \&Related diseases) given either by the experts or some political delegates. But, insignificant degree of the data show that as there was inheritance marriage practices in peripheral areas of the region.

- The extent of bride wealth payment was in very high practice on the indigenous people of the region, more particular in the Gumuz, Shinasha and Berta society.

- Domestic violence practice against women and girls were very high among the indigenous society (Relatively high in Gumuz woman).

- Skin cutting was practiced to some extent in the region, but recently the study reveals that the practice has decreased with very low practice in the society.

- The impact of mal-traditional practices-Festivals, Marriage related practices such as Early marriage, Abduction marriage, and Inheritance marriage, Domestic violence against women and girls as well as Skin cutting were highly realized and affected the socio-economic and health condition of the community.

- It was found out that there existed opposite interrelation between knowledge gaps, and level of practice on MTP's and the effect of loss of government policy implementations. In connection with this, the study comes up with knowledge gap challenge and level of practice affects the socio-economic and health aspects of the indigenous people in the region.

In general, the indigenous people of the region are with mal-traditional practice -bride wealth marriage though others were showing positive progress. Generally, it could be concluded as there are mal-traditional practices on areas where indigenous groups live in the region. From the above writing one could generalize it as in Gumuz areas more particularly in Kamashi zone, there was high wage for bride wealth payment which advocates and paves ways to abduction marriage and exposing the youths for prostitution. Economically, the brides are becoming extravagant users of the money that they already owned sagaciously.

\section{Recommendations}

Based on the key-findings, the following points of recommendation have been forwarded. The regional government should employ new strategies that can help reduce the degree of prevalence of MTPs. For instance, the government should encourage community conversation to reinforce and improve the society's level of understanding further and thereby to reduce the likelihood of prevalence of MTP's. It should be underlined that there ought to be an intervention mechanism that can improve the situations of MTP's in Benishangul Gumuz region. Project has to be designed more particularly on the Peripheral rural kebele to eliminate mal-traditional practices. Intensive training needs to be organized. Laws should be practiced for those who breached it. Thus, regional government need to prepare umbrella that governs the violators.

The Benishangul Gumuz Region Gender Affairs, Government policy makers, Non- governmental organizations and other stakeholders should have great commitment in expelling ma-traditional practices among the society and propel only traditions that favors these people. This study indicated that the society's socioeconomic and cultural factors and multifarious other factors contributed a lot to the prevalence of MTP's. Therefore, remedial works should be made on each of the factors that might push the society to practice. Thus, it is alluded from the analysis that if these factors are avoided or reduced, it is likely that the practice of MTP's can be reduced greatly. As a long run strategies, the regional government should apply family and school based strategies to drain MTP's in particular and gender inequality in general from the grass roots.

\section{References}

AbebeAno(2010). The Shinasha of Metekkel: Northwestern Ethiopia: A Historical Survey to 1974.

Amare Dejene\& Aster Birhanselase(2006): Baseline Survey on Female Genital Mutilation and other Mal-traditional Practice, in North Gondar Amhara Regional State.

AtnafuMorka(2009): Decentralization and Town Development in Benishangul-Gumuz Regional State.

Awoke Bayehetail (2015):The Status of Society's Knowledge, Attitude and Practice of Mal-traditional Practice: The Case of Amhara Regional State, Ethiopia; bureau of 
women, children and youths' affairs.

Drmorissandakouyaté (2009):Mal-traditional Practice against women and legislation.

Facts About Benishangul Gumuz Region (2007): Culture and truism of Benishangul Gumuz Region.

History and Culture of the Benishangul Gumuz People: A paper presented on the 9th Nations, Nationalities and People Day: August: 2007.

Johnson, R. B., \& Turner, L. A. (2003): Data collection strategies in mixed methods research. In A. Tashakkori\& C. Teddlie (Eds.), Handbook of mixed methods in social and behavioral research (pp. 297-319). Thousand Oaks, CA: Sage.

KahsuGebrekiros, MesfinAbebe and AtseduFentahun (2013):Across sectional study on factors associated with Mal-traditional Practice among children less than 5 years in Axum town, north Ethiopia.

KalkidanBekele (2007): cultural practices that affected the status of women in BenishangulGumuzMandura Woreda.

Koshy,V.(2005): Action Research Planner. Geelong, Victoria. Deaking University Press.

MFED (2012): Progress in abandoning female genital mutilation / cutting and child marriage in self-declared Woredas.

Paul J. Lavrakas(2008):Encyclopedia of SurveyResearch Methods; vol.1and 2

Selinger, H.W., and E.Showhamy (1989): Second language Research Methods .Oxford:-Oxford university press.

History and Culture of the Benishangul Gumuz People: A paper presented on the 9th Nations, Nationalities and People Day: August: 2007.

The National Committee on Traditional Practices in Ethiopia (NCTPE) 2001.

WAO, 1992 E.C. A Survey Study on "Early Marriage” in Amhara National Region.

Women's Affairs Office, Amhara National Regional State, BahirDar. (Unpublished Amharic Document).

The Advocates for Human Rights (2010): Types\& Prevalence of Harmful Traditional Practices.

Convention on the Elimination of All forms of Discrimination againstWomen (CEDW) 1979; Harmful Traditional Practices Affecting the Health of Women andChildren; Fact Sheet No.23

United Nations Division for the Advancement of Women United Nations Economic Commission for Africa: 2009: Harmful traditional practices against women and legislation:

Adeyi, A, Adoga and Tonga L. Nimkur (2011). The traditional Amputated Uvula amongst Nigerians: still an ongoing practice. ISRN Otolaryngology 2011, http://dx.doi.org/105402/2011/704924. Assessed August 9, 2013.

Amare Dejene and Aster Birhanerselase(2006). Baseline Survey on Female Genital Mutilation and other Harmful Traditional Practices, in North Gondar Amhara Regional State. Addis Ababa: Save the Children Norway Ethiopia (SCNE).

BirhanRaswork. (2006).The impact of harmful traditional practices on the girl child. UNCIEF. Florence,Italy:Innocenti Research Centre.

Chia Longman \&TamsinBradley (2015). Interrogating Harmful Cultural Practices: Gender, Culture and Coercion London: Ashgate.

Committee on the Status of Women. (2007).Research report on glossary of violence against women. Geneva, Switzerland.

Central Statistical Authority Ethiopia. (2006). Ethiopia Demographic and Health Survey, 2005. CSA and ORC Macro.

Ethiopia Public Health Training Initiative (2005).Harmful Traditional Practices. Awassa: USAID.

Federal Democratic Republic of Ethiopia (FDRE). (1995). The Constitution of the Federal Democratic Republic of Ethiopia. Addis Ababa, Ethiopia.

Hobes,A.,D. \& Blank, J.,S. (2002). Sociology and the human experience. New York, John wiley and sons.

Kothari (2004). Research Methodology. New Age International (P) Ltd.

Lindner, M. (2008). The Social Dimension of Female Genital Cutting (FGC): The Case of Harari. Addis Ababa University, School of Graduate Studies, College of Social Sciences, Department of Sociology and Social Anthropology, Addis Ababa.

National Committee on Traditional Practice in Ethiopia (NCTPE). (2003). Old from imagining. Addis Ababa, Ethiopia.

National Committee on Traditional Practice in Ethiopia (NCTPE). (1999). Resource material on harmful traditional practices for policy makers. Addis Ababa, Ethiopia.

Ngunshi, R.B. (2011). Breast ironing: A harmful traditional practice in Cameroon.Cameroon.

Oxfam. (2005). Beyond the Mainstream: Education for Nomadic and Pastoralist Girls and Boys. Oxfam House. Retrieved from http://www.oxfam.org.uk/.

Shell-Duncan, B. (2008) 'From Health to Human Rights', American Anthropologist 1110.2: 225-36. 
Southern Nation's, Nationalities and People's Region (SNNPR), Bureau of Statics and (BOFS). (2005). The study of Harmful Traditional Practices on demographic structure and socio-economic development in SNNPR. Addis Ababa, Ethiopia.

The Scuurpine, R. and Decorse, c. (2009). Anthropology a global perspective (6 ${ }^{\text {th }}$ d). New Delhi, India. PHI learning.

UNIFPA. (2006). In ending child marriage: A guide for global policy action International Planned Parenthood Federation and the Forum on Marriage and the Rights of Women and Girls. U.K.

United Nations Children's Fund (UNICEF) (2001). Early marriage: child spouses. Florence, Italy: Innocenti Research Centre.

United Nations Children's Fund (UNICEF). (2005). Early marriage: A harmful traditional practice. New York, USA.

United Nations Children's Fund (UNICEF). (2007). UNICEF's experience in the area of legislative reform: $A$ review of Selected Countries. New York: UNICEF.

United Nations Children's Fund (UNICEF).(2006).The impact of harmful traditional practices on the girl child: Florence,Italy:Innocenti Research Centre.

United Nations Centre for Human Rights (UNCHR). (1995). Harmful Traditional Practices Affecting the Health of Women and Children. Geneva: Human Rights Fact Sheet, No.23 Retrieved from http://www.unhchr.ch/html/menu6/2/fs23.htm

United Nations (UN).(2009).Harmful Traditional Practices Against Women and Legislation. Addis Ababa, Ethiopia: United Nations Economic Commission for Africa.

World Health Organization (2010) 'Female Genital Mutilation', WHO Fact Sheet Number 241: February 2010, http://www.who.int/mediacentre/factsheets/fs241/en/

Women's International Network (2000). Community radio is a great way for women to communicate. Women's International Network of AMARC - Women Action.

Ye Ethiopia GojiLimadawiDirgitochAswogajMahiber (EGLDAM) (2008). Follow Up Survey On the Harmful Traditional Practices in Ethiopia. Addis Ababa, Ethiopia.

Ye Ethiopia GojiLimadawiDirgitochAswogajMahiber (EGLDAM) (2011).Follow Up Survey On the Harmful Traditional Practices in Ethiopia. Addis Ababa: Ethiopia. The former national committee for traditional practices of Ethiopia-NCTPE/ .AddisAbaba, Ethiopia. 